\title{
Vincetoxicum canescens subsp. canescens ve Vincetoxicum cancescens subsp. pedunculata Tohumlarının Antimikrobiyal ve Antiproliferatif Aktiviteleri *
}

\author{
Antimicrobial and Antiproliferative Activities of Vincetoxicum canescens subsp. canescens and
}

Vincetoxicum cancescens subsp. pedunculata Seeds

Sevda Güzel', Mahmut Ülgerii, Yusuf Özayiii, Önder Yumrutaşiv, ibrahim Bozgeyikv', Özkan Sarıkayavi

i Dr. Öğr. Üyesi, Mersin Üniversitesi, Eczacılık Fakültesi, Farmakognozi A.D. https://orcid.org/0000-0002-6642-5824

ii Dr. Öğr. Üyesi, Mersin Üniversitesi, Eczacılık Fakültesi, Farmasötik Mikrobiyoloji A.D. https://orcid.org/0000-0001-6649-4195

iii Dr. Öğr. Üyesi, Adıyaman Üniversitesi, Tıp Fakültesi, Tıbbi Biyoloji A.D. https://orcid.org/0000-0003-3855-6197

iv Doç. Dr. Adıyaman Üniversitesi, Tıp Fakültesi, Tıbbi Biyoloji A.D. https://orcid.org/0000-0001-9657-8306

${ }^{\vee}$ Dr. Adıyaman Üniversitesi, Tıp Fakültesi, Tıbbi Biyoloji A.D. https://orcid.org/0000-0003-1483-2580

viDr. Öğr. Üyesi, Kırşehir Ahi Evran Üniversitesi, Sağlık Yüksek Okulu, Çocuk Gelişimi Bölümü https://orcid.org/0000-0002-1641-457X

öz

Vincetoxicum cinsinin tıbbi özellikleri uzun zamandır bilinmektedir. Bazı Vincetoxicum türlerinin yaprakları, kuru tohumları ve rizomları geleneksel tıpta incinme, uyuz, nevroz, skrofula, sıtma, yara, ateş, rüptür ve eksternal kanserlerin tedavisinde kullanılmaktadır. Bu çalışma, $V$. canescens subsp. canescens ve $V$. cancescens subsp. pedunculata (endemik) tohumlarının anti(miko)bakteriyel, antifungal ve antiproliferatif aktivitelerini değerlendirmeye odaklanmıştır. İki bitkinin tohumlarının etanol ve hekzan ekstreleri üç fungal suşa (Candida albicans, Candida tropicalis ve Candida glabrata), iki Gram-pozitif bakteri suşuna (Bacillus subtilis ve Staphylococcus aureus), üç Gram-negatif bakteri suşuna (Aeromonas hydrophila, Escherichia coli ve Acinetobacter baumannii) ve Mycobacterium tuberculosis H37Rv suşuna karşı Sıvı Mikrodilüsyon Yöntemi kullanılarak test edilmiştir. Referans ilaçlar olarak Flukonazol, Etambutol, Ampisilin ve İzoniazid kullanılmıştır. Etanol ve hekzan ekstrelerinin farklı konsantrasyonlarının (200, 100, 50 ve $25 \mu \mathrm{g} / \mathrm{mL}$ ) antiproliferatif etkileri MTT testi kullanılarak A549 insan akciğer kanseri hücre dizilerine karşı test edilmiştir. Etanol ekstrelerinin A. baumannii'ye $(62.5 \mu \mathrm{g} / \mathrm{mL}$ MiK değeri) karşı Ampisilin'den (125 $\mathrm{g} / \mathrm{mL}$ MiK değeri) daha etkili olduğu bulunmuştur. A549 insan akciğer kanseri hücre dizilerine karşı $V$. canescens subsp. canescens tohumlarının etanol ekstresinin $100 \mu \mathrm{g} / \mathrm{mL}$ konsantrasyonu ve $V$. cancescens subsp. pedunculata tohumlarının etanol ekstresinin $200 \mu \mathrm{g} / \mathrm{mL}$ konsantrasyonu, kontrol gruplarına göre istatistiksel olarak daha düşük hücre canlılık seviyeleri sergilemiştir $(P<0.05)$. Sonuç olarak, $V$. canescens subsp. canescens ve $V$. cancescens subsp. pedunculata tohumları, test edilen tüm mikroorganizmalara karşı antimikrobiyal ve A549 insan akciğer kanseri hücre dizilerine karşı antiproliferatif etki göstermiştir; ayrıca, etanol ekstreleri hekzan ekstrelerinden daha etkili bulunmuştur.

Anahtar kelimeler: Vincetoxicum, Tohum, Antimikrobiyal, Hücre canlılı̆ı

\section{ABSTRACT}

Medicinal properties of Vincetoxicum genus have been known for a long time. Leaves, dry seeds, and rhizomes of some Vincetoxicum species have been used in folk medicine for the treatment of injuries, scabies, neurosis, scrofula, malaria, wound, fever, rupture, and external cancers. The present study focused on evaluating anti(myco)bacterial, antifungal, and antiproliferative activities of seeds of $V$. canescens subsp. canescens and $V$. cancescens subsp. pedunculata (endemic). Ethanol and hexane extracts of seeds of two plants were tested against three fungal strains (Candida albicans, Candida tropicalis, and Candida glabrata), two Gram-positive bacterial strains (Bacillus subtilis and Staphylococcus aureus), three Gram-negative bacterial strains (Aeromonas hydrophila, Escherichia coli, and Acinetobacter baumannii), and Mycobacterium tuberculosis H37Rv using broth microdilution method. Fluconazole, Ethambutol, Ampicillin, and Isoniazid were used as reference drugs. Antiproliferative effects of various concentrations $(200,100,50$, and $25 \mu \mathrm{g} / \mathrm{mL}$ ) of ethanol and hexane extracts were tested against A549 human lung cancer cell lines using MTT test. The ethanol extracts were found to be more effective against $A$. baumannii $(62.5 \mu \mathrm{g} / \mathrm{mL} \mathrm{MIC}$ value) than Ampicillin (125 $\mathrm{\mu g} / \mathrm{mL}$ MIC value). Against A549 human lung cancer cell lines, $100 \mu \mathrm{g} / \mathrm{mL}$ concentration of ethanol extract of $V$. canescens subsp. canescens seeds and $200 \mu \mathrm{g} / \mathrm{mL}$ concentration of ethanol extract of $V$. cancescens subsp. pedunculata seeds were exhibited statistically lower cell viability levels than control groups $(P<0.05)$. As a result, $V$. canescens subsp. canescens and $V$. cancescens subsp. pedunculata seeds showed antimicrobial and antiproliferative effects against all tested microorganisms and A549 human lung cancer cell lines; moreover, ethanol extracts were found to be more effective than hexane extracts.

Key Words: Vincetoxicum, Seed, Antimicrobial, Cell viability

*Lokman Hekim Dergisi, 2019; 9 (3): 367-375

DOI: $10.31020 /$ mutftd.594212

e-ISSN: $1309-8004$

Geliş Tarihi - Received: 19 Temmuz 2019; Kabul Tarihi - Accepted: 2 Eylül 2019

Iletişim - Correspondence Author: Sevda Güzel <guzelsevda@mersin.edu.tr> 


\section{GíRiş}

Geleneksel kullanımları, fitokimyasal bileşimleri ve farmakolojik etkileri nedeniyle bitkiler uzun zamandır dikkatleri üzerine çekmektedir. ${ }^{1}$ Literatürde bitkilerin tedavi edici etkilerini gösteren çok sayıda çalışma olup; 20.000 'den fazla tıbbi bitkinin zatürre, diyare, ülser, soğuk algınlığı, bronşit ve solunum yolu hastalıkları gibi çeşitli hastalıkların tedavisinde kullanıldı̆̆ı Dünya Sağlık Örgütü tarafından bildirilmiştir. ${ }^{2}$ Kendilerine karşı kullanılan antimikrobiyal ilaçlara karşı mikroorganizmaların direnç geliştirme potansiyelleri bulunmaktadır. İlaca dirençli suşlar nedeniyle mikroorganizmaların yol açtığı bulaşıcı hastalıklar Dünya genelinde ciddi sağlık sorunlarına neden olmaktadır. Dahası yüksek maliyetli sentetik ilaçlar ve istenmeyen yan etkiler enfeksiyon hastalıkları ile etkili mücadelede farklı hareket mekanizmalarına sahip yeni antimikrobiyal ajanların keşfinin gerekliliğini ortaya koymaktadır. ${ }^{3}$ Tıbbi bitkiler, bunlardan elde edilen ekstre ve bileşikler antioksidan, antimikrobiyal, antikanser, antienflamatuvar ve yara iyi edici etkileri nedeniyle birçok hastalığın tedavisinde alternatif tedavi stratejileri geliştirilmesine kaynak oluşturmaktadır. ${ }^{4}$ Günümüzde birçok farmakolojik etki, düşük maliyet, elde edilebilirlik gibi özelliklere ek olarak yüksek etki ve düşük yan etki bitki ve bitkilerden elde edilen ürünlerin önemini daha da arttırmaktadır. ${ }^{5}$

Vincetoxicum N.M. Wolf cinsi (Apocynaceae: subfamilya Asclepiadoideae) yaklaşık 100 türü bulunan Kuzey Amerika ${ }^{6}$, Avrupa, Asya ve Japonya' da ${ }^{7}$ yayılış gösteren bir cinstir. Vincetoxicum cinsine ait türlerin kökleri, yaprakları ve kuru tohumları tıbbi özellikleri nedeniyle uzun zamandır geleneksel tıpta kullanılmaktadır. ${ }^{8} \mathrm{~V}$. hirundinaria Medicus, V.nigrum (L.) Moench ve V. stocksii Ali \& Khatoon türleri geleneksel olarak Avrupa ve Çin tedavi sistemlerinde incinme, uyuz, nevroz, skrofula, sıtma, yara, ateş ve rüptür tedavilerinde kullanılmakta ${ }^{8,9,10}$; antitümör ${ }^{9,11}$, antilayşmanyal ${ }^{10}$, diyaforetik ve laksatif ${ }^{9}$ etkileri bilinmektedir. $V$. stocksii türünden elde edilen lapa Pakistan'da eksternal kanserlerin ve yaraların tedavisinde kullanılmaktadır. ${ }^{10} \mathrm{~V}$. hirundinaria türünün kökleri veteriner hekimlikte çeşitli hastalıkların tedavisinde ve ödemde kullanılmakla ${ }^{9}$ birlikte, bitki Fransa'da "dompte-venin" ismiyle bilinmekte ve emetik ve ekspektoran özellikleri nedeniyle kullanılmaktadır ${ }^{12}$. İtalya'da ise aynı türün toprak üstü kısımları ve köklerinden elde edilen dekoksiyon ve infüzyonlar zehirlenmelere karşı antidot olarak kullanılırken ${ }^{13}$, bitki Türkiye'de "Panzehir otu ve Kırlangıç kuyruğu" olarak adlandırılmakta ve köklerin emetik etkisi bilinmektedir ${ }^{14}$. V. canescens subsp. canescens (Willd.) Decne. türü Tunceli (Ovacık) yöresinde "zehir otu"15 yerel ismiyle bilinmekte olup, ezilmiş meyve ve yaprakları fungal enfeksiyonların tedavisinde haricen kullanılmaktadır ${ }^{15,16}$. Ayrıca $V$. canescens subsp. canescens ve $V$. tmoleum Boiss. türleri Doğu Anadolu Bölgesi'nde "Zilasur" yerel ismi ile bilinmekte olup uyuz tedavisinde dövülmüş halde dışardan kullanımları bildirilmiştir. ${ }^{16}$ Geleneksel kullanımlarına ek olarak cinse ait türlerin sitotoksik, antikanser ${ }^{17}$, antifungal, antibakteriyal ${ }^{10,18-20}$, antilayşmanyal, antimalaryal ${ }^{10}$ ve antioksidan ${ }^{8}$ aktiviteleri de rapor edilmiştir.

Bugüne kadar yapılan fitokimyasal araştırmalar bu cinse ait türlerin triterpenler, steroidal glikozitler, steroidler, alkanoller ${ }^{11}$, fenantroindolizidin alkaloitleri ${ }^{17,21}$, saponinler, şeker, nişasta ${ }^{22}$, flavonoit ve tanen ${ }^{21}$ içerdiğini bildirmiştir.

Türkiye'de Vincetoxicum cinsi 3'ü endemik olmak üzere 10 takson ile temsil edilmektedir. ${ }^{23}$ Türkiye'de doğal olarak yetişen Vincetoxicum cinsine ait türler üzerinde aktivite çalışmaları ilk kez çalışma grubumuz tarafından önceki araştırmalarımızda yapılmıştır. ${ }^{19-22,24}$ Literatür taramalarında Vincetoxicum cinsinin tohumları üzerine yapılmış herhangi bir biyoaktivite çalışmasına rastlanmamıştır. Bu nedenle bu çalışmada; Türkiye'de doğal olarak yetişen ve biri endemik olan iki Vincetoxicum taksonunun [V. canescens subsp. canescens ve $V$. cancescens (Willd.) Decne. subsp. pedunculata Browicz (endemik)] tohumlarından elde edilen etanol ve hekzan ekstrelerinin in vitro anti(miko)bakteriyal, antifungal ve antiproliferatif aktivitelerinin araştırılması amaçlanmıştır.

\section{YÖNTEMLER}

\section{Bitki materyali ve ekstraksiyon prosedürü}

$V$. canescens subsp. canescens ve $V$. cancescens subsp. pedunculata Türkiye'nin iki farklı bölgesinden toplanmış ve teşhisleri Dr. Sevda Güzel ve Dr. Ahmet Illçim tarafından yapılmıştır. ${ }^{23}$ Bitki materyallerine ait herbaryum örnekleri Mustafa Kemal Üniversitesi herbaryumunda saklanmakta olup örneklere ait detaylı bilgiler Tablo 1'de verilmiştir. 
Tablo 1. Çalışılan taksonlara ait bilgiler

\begin{tabular}{|c|c|c|}
\hline & \multicolumn{2}{|c|}{ Çalışılan Taksonlar } \\
\hline & $\begin{array}{l}\text { V. canescens subsp. canescens (Willd.) } \\
\text { Decne. }\end{array}$ & $\begin{array}{l}\text { V. canescens subsp. pedunculata } \\
\text { Browicz }\end{array}$ \\
\hline Endemik takson* & - & Endemik \\
\hline Lökalite* & C6: Kahramanmaraş, Engizek Dağı & B3: Afyon, Dinar; Kumalar Dağı \\
\hline Fitocoğrafik orjin* & İran-Turan elementi & Doğu Akdeniz elementi \\
\hline Toplama zamanı & 13.07 .2016 & 20.07.2016 \\
\hline Yükseklik (m) & 1.000 & $1.500-1.600$ \\
\hline Herbaryum numarası & MKUH 1283 & MKUH 1284 \\
\hline $\begin{array}{l}\text { Etanol ekstre verimi (mg/g kuru } \\
\text { örnek) }\end{array}$ & 240.15 & 248.95 \\
\hline $\begin{array}{l}\text { Hekzan ekstre verimi (mg/g kuru } \\
\text { örnek) }\end{array}$ & 206.6 & 210.2 \\
\hline
\end{tabular}

${ }^{*}$ Türkiye Florasına göre düzenlenmiştir. ${ }^{23}$

Öğütülen tohumlar \%96'lık etanolle (1 g tohum materyali: $20 \mathrm{~mL}$ etanol) oda sıcaklığında bir gece karıştırıcıda (Stirrer DLS-Velp Scientifica) karıştırılarak bekletildikten sonra süspansiyon Whatman No.1 filtre kâğıdından süzülmüş ve kalan artık üzerine etanol eklenerek aynı işlem bir kez daha tekrarlanmıştır. Birleştirilen süzüntüler düşük sıcaklıkta rotary-evaporatörde (Heidolph-Rotary TLR 1000) uçurulmuş, elde edilen etanol ekstreleri kullanılana kadar $+4^{\circ} \mathrm{C}$ 'de karanlıkta muhafaza edilmiştir. Hekzan ekstresi için ise toz edilmiş tohumlar Soxhlet cihazında 6 saat süreyle ekstre edilmiş ve sonrasında çözücü rotary-evaporatörde uçurulmuştur. Elde edilen hekzan ekstreleri kahverengi şişelere konarak kullanılana kadar oda sıcaklığında muhafaza edilmiştir.

\section{Antimikrobiyal aktivite}

Mikroorganizmalar: Bakteri suşları Staphylococcus aureus (ATCC 25925), Bacillus subtilis (ATCC 6633), Escherichia coli (ATCC 25923), Acinetobacter baumannii (ATCC 02026), Aeromonas hydrophila (ATCC 95080), Mycobacterium tuberculosis H37Rv, ve fungal suşlar Candida albicans (ATCC 14053), Candida tropicalis (ATCC 1369) ve Candida glabrata (ATCC 15126) Refik Saydam Hıfzıssıhha Enstitüsü'nden (Ankara) temin edilmiştir.

\section{Antibakteriyal aktivite}

$V$. canescens subsp. canescens ve $V$. canescens subsp. pedunculata tohumlarından elde edilen etanol ve hekzan ekstreleri iki Gram-pozitif ( $S$. aureus ve B. subtilis) ve üç Gram-negatif (E. coli, A. baumannii ve A. hydrophila) standart bakteri suşuna karşı Sıvı Mikrodilüsyon Yöntemi kullanılarak in vitro antibakteriyal aktiviteleri için test edilmiştir. Ampisilin çalışmada referans antibakteriyal ilaç olarak kullanılmıştır. Ekstreler dimetil sülfoksitde (DMSO) çözülerek $2000 \mu \mathrm{g} / \mathrm{mL}$ konsantrasyonda stok solüsyonları hazırlanmıştır. Steril mikroplak kuyularına Mueller-Hinton sıvı besiyerinden ve çözünmüş ekstrelerden eklendikten sonra bir seri seyreltme işlemi ile test edilecek ekstrelerin konsantrasyonları 1000, 500, 250, 125, 62.5, 31.25, 15.62, 7.8, 3.9 ve $1.9 \mu \mathrm{g} / \mathrm{mL}$ olarak ayarlanmıştır. Her bir standart bakteri suşundan ayrı ayrı steril tüplerde 0.5 McFarland yoğunluğunda bakteri süspansiyonları hazırlanmış ve bu süspansiyonlar steril distile su ile 1:20 oranında seyreltilmiştir. Süspansiyonlardan, içerisinde besiyeri ve ekstre bulunan her bir kuyuya $10 \mu \mathrm{L}$ eklenmiştir. Böylelikle kuyulardaki son bakteri yoğunluğu $5 \times 10^{5} \mathrm{CFU} / \mathrm{mL}$ 'ye ayarlanmıştır. Aynı işlem Ampisilin içinde yapılmış ve aynı seyreltme serisi elde edilmiştir. Çözücünün (DMSO) mikrobiyal büyüme etkisi de araştırılmış ve test edilen mikroorganizmalar üzerinde etkisinin olmadığı belirlenmiştir. Deneyler iki tekrarlı yapılmış ve her bir ekstrenin minimum inhibitör konsantrasyon (MiK) değeri belirlenmiştir. ${ }^{4}$

\section{Antimikobakteriyal aktivite}

Etanol ve hekzan ekstreleri $M$. tuberculosis H37Rv standart suşuna karşı Resazurin Mikroplak Yöntemi ile in vitro antimikobakteriyal aktiviteleri için test edilmiştir. Çalışmada $\% 0.1$ kaziton, $\% 0.5$ gliserol ve $\% 10$ oleik asit-albümin-dekstroz-katalaz (Becton Dickinson) ile zenginleştirilmiş Middlebrook 7H9 besiyeri (Becton Dickinson) bazlı 7H9-S besiyeri kullanılmıştır. Resazurin çalışma solüsyonu distile su kullanılarak \%0.01 (a/h) konsantrasyonda hazırlanmış ve membran filtreden (çap: $0.22 \mu \mathrm{m}$ ) geçirilerek steril edilmiştir. İzoniazid (Sigma, 13377) ve Etambutol (Sigma, E4630) referans ilaçlar olarak kullanılmıştır. Ekstrelerin ve referans 
ilaçların DMSO'da $2000 \mu \mathrm{g} / \mathrm{mL}$ konsantrasyonda stok solüsyonları hazırlanmış ve membran filtrelerden (çap: $0.22 \mu \mathrm{m}$ ) geçirilerek steril edilmiştir. Solüsyonların iki kat seri seyreltmeleri 96 kuyulu mikroplaklarda 7H9-S besiyeri $(100 \mu \mathrm{L})$ ile yapılmış ve böylelikle $250-0.12 \mu \mathrm{g} / \mathrm{mL}$ aralığında konsantrasyon değerleri elde edilmiştir. Her bir plağa ayrıca standart antibiyotik içermeyen bir üreme kontrolü ve inokulum içermeyen bir sterilite kontrolü eklenmiştir. Löwenstein-Jensen besiyerinde üretilen H37Rv kolonilerinden bir öze dolusu alınarak, $5 \mathrm{~mL}$ 7H9-S besiyerinde süspanse edilmiştir. Süspansiyon 2 dakika vortekslenmiş ve sonra 30 dakika hareket ettirilmeden bekletilerek büyük partiküllerin ve besiyeri kalıntılarının dibe çökmesi sağlanmıştır. Süre sonunda süpernatant yeni bir steril tüpe aktarılmış ve besiyeri ile McFarland No:1 bulanıklık değerinde süspansiyon hazırlanmıştır. Hazırlanan süspansiyon 7H9-S besiyeri ile 1:20 oranında seyreltilmiştir. Bu süspansiyondan $100 \mu \mathrm{L}$, plak kuyularına eklenmiş; plaklar parafilm ile kapatılmış ve $37^{\circ} \mathrm{C}$ de normal atmosferde 7 gün boyunca inkübasyona bırakılmıştır. İnkübasyon sonunda tüm kuyulara resazurin çalışma solüsyonu (30 $\mu \mathrm{L}$ ) eklenerek plaklar 1 gün daha inkübe edilmiş ve sonuçlar görsel olarak değerlendirilmiştir. Çözücünün (DMSO) büyüme etkisi de test edilmiş, etkisinin olmadığı belirlenmiştir. Çalışma çift tekrarlı yapılmıştır. Resazurin'in renginin maviden pembeye dönmesi resazurinin redükte olduğunu, yani kuyuda bakteri ürediğini gösterir. MiK değeri, maviden pembeye renk değişimini engelleyen en düşük konsantrasyon olarak belirlenmiştir. ${ }^{4}$

\section{Antifungal aktivite}

Etanol ve hekzan ekstrelerinin in vitro antifungal aktiviteleri $C$. albicans, $C$. tropicalis ve $C$. glabrata fungal suşlarına karşı NCCLS/M27-A2 ${ }^{25}$ standart protokolü kullanılarak Sıvı Mikrodilüsyon Yöntemi ile araştırılmıştır. ${ }^{4}$ Flukonazol (Sigma, F8929) referans antifungal ilaç olarak seçilmiştir. Deneylerde, $0.165 \mathrm{M} 3-$ (N-morfolino)-propansülfonik asit (Sigma, M1254) ile pH'sı 7.0'a ayarlanmış RPMI 1640 besiyeri (Sigma, R6504) kullanılmıştır. Standart suşların RPMI 1640 besiyerinde 1:100 daha sonra 1:20 seyreltilmiş çalışma süspansiyonları hazırlanmıştır. DMSO'da ekstrelerin ve standart ilacın $1000 \mu \mathrm{g} / \mathrm{mL}$ konsantrasyonda stok solüsyonları hazırlanmış ve membran filtreden geçirilerek (çap: $0.22 \mu \mathrm{m}$ ) steril edilmiştir. Solüsyonların iki kat seri seyreltmeleri RPMI 1640 besiyeri kullanılarak 96 kuyulu mikroplaklarda yapılmış ve böylelikle 250$0.12 \mu \mathrm{g} / \mathrm{mL}$ aralığında konsantrasyon değerleri elde edilmiştir. Her plağa standart antibiyotik içermeyen bir üreme kontrolü ve inokulum içermeyen bir sterilite kontrolü eklenmiştir. Her kuyuya $100 \mu \mathrm{L}$ hazırlanan inokulum süspansiyonundan eklenmiş, plaklar $35^{\circ} \mathrm{C}^{\prime}$ de normal atmosferde 48 saat inkübe edilmiş ve sonuçlar görsel olarak değerlendirilmiştir. Çözücünün (DMSO) büyüme etkisi de test edilmiş, etkisinin olmadığı belirlenmiştir. Mik değerleri, test edilen ekstrelerin üremeyi inhibe eden en düşük konsantrasyonları olarak belirlenmiştir. ${ }^{4,25}$

\section{Antiproliferatif aktivite}

Hücre kültürü: Çalışmada A549 insan akciğer kanseri hücre dizileri (ATCC-Amerikan Tip Kültür Koleksiyonu) kullanılmıştır. Hücre kültürü için \%10 fetal kalf serumu (Sigma-Aldrich) içeren DMEM (Sigma-Aldrich) kullanılmıştır. Hücreler $37^{\circ} \mathrm{C}$ sıcaklıkta $\% 95$ hava ve $\% 5$ karbondioksit içeren uygun kültür ortamında tutulmuştur.

\section{Hücre canlılı̆ının değerlendirilmesi}

Hücre canlılı̆ı, MTT (3- [4,5- dimetiltiazol- 2- yl]- 2,5- difenil- tetrazolium bromit) yöntemi ile test edilmiştir. Hücreler kültür ortamında \%70-80 yoğunluğa ulaştıktan sonra $3.0 \mathrm{~mL}$ Trypsin-EDTA solüsyonu (Sigma) yardımıyla 96 kuyulu mikroplaklara yerleştirilmiştir (her kuyucuğa $10^{4}$ hücre gelecek şekilde). 24 saat inkübasyon sonunda ekstrelerin DMSO ile hazırlanan farklı seyreltmeleri $(25,50,100$ ve $200 \mu \mathrm{g} / \mathrm{mL})$ kuyulara ilave edilmiş ve 24 saat inkübasyona bırakılmıştır. Pozitif kontrol olarak \%10 FKS içermeyen besiyerinde bekletilen hücreler kullanılmış. İnkübasyon sonunda süpernatant $1 \mathrm{mg} / \mathrm{mL}$ MTT (Sigma-Aldrich) içeren besiyeri ile değiştirilerek $37^{\circ} \mathrm{C}$ de mor renkli çökelti gözlenene kadar inkübasyona bırakılmıştır. Sonrasında MTT solüsyonu ortamdan uzaklaştırılarak hücrelerin üzerine DMSO eklenmiştir. Sonuçlar spektrofotometre (Epoch) yardımıyla $550 \mathrm{~nm}$ dalga boyunda okunarak hücre canlılı̆ı tespit edilmiştir. DMSO'nun da hücre canlılığı üzerine etkisi test edilmiş ve istatistiksel olarak anlamlı bir etkisinin olmadığı bulunmuştur. Çalışma 4 tekrarlı yapılmıştır. ${ }^{26}$ 


\section{İstatistik analizler}

İstatistiksel analizler SPSS 25.0 (IBM) ve MS Office Excel (Microsoft) programları kullanılarak yapılmıştır. Veriler ortalama \pm Standart sapma olarak gösterilmiştir. Kruskal Wallis $\mathrm{H}$ ve ANOVA testleri kullanılmıştır. $\mathrm{P}$ $<0.05$ değerleri istatistiksel olarak anlamlı kabul edilmiştir.

\section{BULGULAR}

Çalışmada Türkiye'de doğal olarak yetişen ve biri endemik olan $V$. canescens subsp. canescens ve $V$. canescens subsp. pedunculata tohumlarından elde edilen etanol ve hekzan ekstreleri anti(miko)bakteriyal, antifungal ve antiprolifetatif aktiviteleri için ilk kez araştırılmış olup çalışılan taksonlara ait detaylı bilgiler ve ekstre verimleri Tablo 1'de verilmiştir.

\section{Antimikrobiyal aktivite}

Antimikrobiyal aktivite sonuçları Tablo 2 'de verilmiştir. $V$. canescens subsp. canescens ve $V$. cancescens subsp. pedunculata tohumlarından elde edilen ekstrelerin test edildikleri 6 bakteriyal ve 3 fungal suşa karşı 250-62.5 $\mu \mathrm{g} / \mathrm{mL}$ aralığında MiK değerleri ile antimikrobiyal aktivite gösterdiği tespit edilmiştir. Her iki taksonda etanol ekstreleri hekzan ekstrelerinden daha etkili bulunmuştur. Her iki taksondan elde edilen etanol ekstreleri A. baumannii'ye karşı $62.5 \mu \mathrm{g} / \mathrm{mL}$ MiK değeri ile referans ilaç Ampisilinden (Mik değeri: $125 \mu \mathrm{g} / \mathrm{mL}$ ) daha etkilidir. Test edilen dört ekstre A. hydrophila'ya karşı (MiK değeri: $125 \mu \mathrm{g} / \mathrm{mL}$ ) ılımlı etki göstermiş olup sonuçlar Ampisilinle (Mik değeri: $31.25 \mu \mathrm{g} / \mathrm{mL}$ ) karşılaştırıldığında etkinlik düşüktür. Antimikobakteriyal aktivite sonuçlarına göre teste edilen ekstrelerin tümü $M$. tuberculosis H37Rv standart suşuna karşı $62.5 \mu \mathrm{g} / \mathrm{mL}$ MiK değeri ile etkilidir. Fakat sonuçlar referans ilaçlar İzoniazid ve Etambutol (sırasıyla MiK değerleri: 0.97 ve $1.95 \mu \mathrm{g} / \mathrm{mL}$ ) ile karşılaştıııldığında etkinliği çok düşüktür. Antifungal aktivite sonuçları, çalışılan türlerin test edilen standart fungal suşlara (C. albicans, C. tropicalis ve $C$. glabrata) karşı 250-62.5 $\mu \mathrm{g} / \mathrm{mL}$ aralı̆̆ında çeşitli MiK değerleri ile etkili olduğunu göstermiştir. Dahası etanol ekstrelerinin (MiK değeri: $62.5 \mu \mathrm{g} / \mathrm{mL}$ ) antifungal aktivitesinin hekzan (MiK değeri: $250 \mu \mathrm{g} / \mathrm{mL}$ ve $125 \mu \mathrm{g} / \mathrm{mL}$ ) ekstrelerininkinden daha yüksek olduğu görülmüştür. Fakat sonuçlar referans ilaç Flukonazol ile karşılaştırıldığında (MiK değerleri: C. albicans, $31.25 \mu \mathrm{g} / \mathrm{mL}$; C. tropicalis, $15.62 \mu \mathrm{g} / \mathrm{mL}$ ve C. glabrata: 3.90 $\mu \mathrm{g} / \mathrm{mL}$ ) etkinlik düşüktür (Tablo 2).

Tablo 2. Bakteriyal ve fungal suşlara karşı test edilen $V$. canescens subsp. canescens ve $V$. canescens subsp. pedunculata tohumlarının ve referans ilaçların MiK değerleri $(\mu \mathrm{g} / \mathrm{mL})$

\begin{tabular}{|c|c|c|c|c|c|c|c|c|}
\hline \multirow[t]{2}{*}{ Mikroorganizmalar } & \multicolumn{2}{|c|}{$\begin{array}{l}\text { V. canescens subsp. } \\
\text { canescens }\end{array}$} & \multicolumn{2}{|c|}{$\begin{array}{l}\text { V. canescens subsp. } \\
\text { pedunculata }\end{array}$} & \multicolumn{4}{|c|}{ Referans ilaçlar } \\
\hline & Etanol & Hekzan & Etanol & Hekzan & Ampisilin & İzoniazid & Etambutol & Flukonazol \\
\hline \multicolumn{9}{|l|}{ Bakteriyal suşlar } \\
\hline Staphylococcus aureus ATCC 25925 & 250 & 250 & 250 & 250 & 31.25 & - & - & - \\
\hline Bacillus subtilis ATCC 6633 & 125 & 250 & 250 & 250 & 0.9 & - & - & - \\
\hline Escherichia coli ATCC 25923 & 250 & 250 & 250 & 250 & 15.62 & - & - & - \\
\hline $\begin{array}{l}\text { Acinetobacter baumannii ATCC } \\
02026\end{array}$ & 62.5 & 250 & 62.5 & 250 & 125 & - & - & - \\
\hline Aeromonas hydrophila ATCC 95080 & 125 & 125 & 125 & 125 & 31.25 & - & - & - \\
\hline Mycobacterium tuberculosis H37Rv & 62.5 & 62.5 & 62.5 & 62.5 & - & 0.97 & 1.95 & - \\
\hline \multicolumn{9}{|l|}{ Fungal suşlar } \\
\hline Candida albicans ATCC 14053 & 62.5 & 250 & 62.5 & 250 & - & - & - & 31.25 \\
\hline Candida tropicalis ATCC 1369 & 62.5 & 250 & 62.5 & 250 & - & - & - & 15.62 \\
\hline Candida glabrata ATCC 15126 & 62.5 & 250 & 62.5 & 125 & - & - & - & 3.90 \\
\hline
\end{tabular}

Çalışma iki tekrarlı yapılmış ve MiK değerleri belirlenmiştir. -: Test edilmedi.

\section{Antiproliferatif aktivite}

Çalışılan türlerin tohumlarından elde edilen etanol ve hekzan ekstrelerinin farklı konsantrasyonları $(25,50$, 100 ve $200 \mu \mathrm{g} / \mathrm{mL}$ ) A549 insan akciğer kanseri hücre dizilerine karşı antiproliferatif etkileri için test edilmiş ve sonuçlar Tablo $\mathbf{3}^{\prime}$ de verilmiştir. $V$. canescens subsp. canescens tohumlarından elde edilen etanol ekstresinin 50, 100 ve $200 \mu \mathrm{g} / \mathrm{mL}$ konsantrasyonlarının uygulandığı gruplarda sırasıyla $0.645 \pm 0.01,0.614 \pm$ 0.009 ve $0.628 \pm 0.026$ değerleri ve hekzan ekstresinin 25 ve $50 \mu \mathrm{g} / \mathrm{mL}$ konsantrasyonlarının uygulandığı gruplarda sırasıyla $0.861 \pm 0.022$ ve $0.875 \pm 0.01$ değerleri ile kontrol gruplarına (sırasıyla $1.079 \pm 0.011$ ve 
$0.994 \pm 0.009)$ göre istatistiksel olarak anlamlı derecede düşük hücre canlılığı düzeyleri tespit edilmiştir ( $P$ $<0.05)$. V. cancescens subsp. pedunculata tohumlarından elde edilen etanol ekstresinin 100 ve $200 \mu \mathrm{g} / \mathrm{mL}$ konsantrasyonlarının uygulandığı gruplarda sırasıyla $0.768 \pm 0.007$ ve $0.709 \pm 0.007$ değerleri ile ve hekzan ekstresinin $50 \mu \mathrm{g} / \mathrm{mL}$ konsantrasyonunun uygulandığı grupta $0.947 \pm 0.027$ değeri ile kontrol gruplarına (sırasıyla $1.089 \pm 0.011$ ve $1.035 \pm 0.016)$ göre istatistiksel olarak anlamlı derecede düşük hücre canlılığı düzeyleri tespit edilmiştir $(\mathrm{P}<0.05)$. Çalışılan diğer gruplar arasında istatistiksel olarak anlamlı bir fark gözlenmemiştir ( $P>0.05)$ (Tablo 3).

Tablo 3. $V$. canescens subsp. canescens ve $V$. canescens subsp. pedunculata tohumlarının A549 İnsan akciğer kanseri hücre dizileri üzerine antiproliferatif etkisi

\begin{tabular}{lcccc}
\hline \multirow{2}{*}{ Gruplar } & \multicolumn{2}{c}{$\boldsymbol{V}$. canescens subsp. canescens } & \multicolumn{2}{c}{ V. canescens subsp. pedunculata } \\
\cline { 2 - 5 } & Etanol & Hekzan & Etanol & Hekzan \\
\hline Kontrol & $1.079 \pm 0.011$ & $0.994 \pm 0.009$ & $1.089 \pm 0.011$ & $1.035 \pm 0.016$ \\
& $(1.071-1.095)$ & $(0.984-1.006)$ & $(1.075-1.098)$ & $(1.015-1.049)$ \\
\multirow{2}{*}{ DMSO } & $1.024 \pm 0.019$ & $0.989 \pm 0.005$ & $1.029 \pm 0.012$ & $1.029 \pm 0.012$ \\
& $(1.006-1.045)$ & $(0.984-0.993)$ & $(1.011-1.037)$ & $(1.011-1.037)$ \\
25 & $0.718 \pm 0.019$ & $0.861 \pm 0.022^{*}$ & $0.828 \pm 0.035$ & $0.996 \pm 0.021$ \\
& $(0.710-0.724)$ & $(0.841-0.891)$ & $(0.794-0.860)$ & $(0.971-1.022)$ \\
50 & $0.645 \pm 0.01^{*}$ & $0.875 \pm 0.01^{*}$ & $0.830 \pm 0.033$ & $0.947 \pm 0.027^{*}$ \\
& $(0.630-0.649)$ & $(0.866-0.889)$ & $(0.798-0.860)$ & $(0.941-0.976)$ \\
100 & $0.614 \pm 0.009^{*}$ & $0.902 \pm 0.023$ & $0.768 \pm 0.007^{*}$ & $0.963 \pm 0.014$ \\
& $(0.610-0.630)$ & $(0.882-0.922)$ & $(0.762-0.777)$ & $(0.943-0.975)$ \\
200 & $0.628 \pm 0.026^{*}$ & $0.936 \pm 0.021$ & $0.709 \pm 0.007^{*}$ & $0.950 \pm 0.023$ \\
& $(0.606-0.651)$ & $(0.917-0.956)$ & $(0.701-0.718)$ & $(0.933-0.984)$ \\
\hline
\end{tabular}

Ölçümler ortalama \pm Standart sapma olarak verilmiştir. Parantez içinde Min-Max değerleri yer alır. Kruskal Wallis $\mathrm{H}$ ve ANOVA testleri kullanılmıştır. $n=4$. $P<0.05$ istatistiksel olarak anlamlıdır. *Kontrol grubundan istatistiksel olarak farklıdır. (Kontrol: hiç bir kimyasal uygulanmayan, sadece besiyerinde tutulan grup; DMSO: Besiyeri ve DMSO uygulanan grup; 25 : $25 \mu \mathrm{g} / \mathrm{mL}$ konsantrasyonda ekstre uygulanan grup; $50: 50 \mu \mathrm{g} / \mathrm{mL}$ konsantrasyonda ekstre uygulanan grup; 100: $100 \mu \mathrm{g} / \mathrm{mL}$ konsantrasyonda ekstre uygulanan grup; 200: $200 \mu \mathrm{g} / \mathrm{mL}$ konsantrasyonda ekstre uygulanan grup).

\section{TARTIŞMA}

Bu çalışma, Türkiye'de doğal olarak yetişen ve biri endemik olan iki Vincetoxicum taksonunun tohumlarının biyolojik aktiviteleri üzerine yapılmış ilk bilimsel çalışmadır.

Literatür taramalarında, Vincetoxicum cinsine ait bazı taksonların farklı kısımları üzerine yapılmış az sayıda antimikrobiyal aktivite çalışmasının olduğu görülmüştür. ${ }^{18-20,24,27,28} \mathrm{~V}$. pumilum Decne. türünden elde edilen metanol ekstresi $B$. subtilis, S. aureus, E. coli ve $C$. albicans'ın da içerisinde olduğu bir grup mikroorganizmaya karşı test edilmiş ve $C$. albicans'a karşı belirgin antifungal aktivitesi olduğu; bakteri suşlarına karşı ise etkili olmadığı görülmüştür. ${ }^{27} \mathrm{~V}$. stocksii türünün metanol ekstresinden elde edilen etil asetat, hekzan, bütanol, kloroform ve su fraksiyonları $C$. albicans'ında içlerinde olduğu 12 fungal suşa ve $B$. subtilis, E. coli ve $S$. aureus'un da içlerinde olduğu 12 bakteriyal suşa karşı antimikrobiyal aktiviteleri için test edilmiş; $B$. subtilis ve $C$. albicans'a karşı belirgin aktiviteli olduğu, $E$. coli'ye karşı ılımlı aktivite gösterdiği ve $S$. aureus karşı ise etkili olmadığı bulunmuştur. ${ }^{18} \mathrm{~V}$. rossicum'un kök, taze yaprak ve olgun meyvelerinden elde edilen etanol ekstreleri çeşitli bakterilere ve funguslara karşı antimikrobiyal aktiviteleri için incelenmiş ve bitkinin antimikrobiyal etkili olduğu, dahası köklerin yapraklardan daha etkili olduğu bildirilmiştir. ${ }^{28}$ Türkiye'de doğal olarak yetişen beş Vincetoxicum taksonunun $(V$. canescens subsp. canescens, $V$. canescens subsp. pedunculata, $V$. fuscatum subsp. fuscatum, $V$. fuscatum subsp. boissieri ve $V$. parviflorum) kök ve toprak üstü kısımlarından elde edilen ekstrelerin (diklorometan, diklorometan: metanol (1:1), metanol ve total etanol) $A$. fumigatus'a karşı $1 \mathrm{mg} / \mathrm{mL}$ konsantrasyonda antifungal aktivitelerine bakılmış ve $V$. parviflorum'un kök ve toprak üstü kısımlarından ve $V$. canescens subsp. canescens'in köklerinden elde edilen diklorometanlı ekstrelerinin \%45.86 inhibisyon değeri ile en yüksek etkiyi gösterdiği bildirilmiştir. ${ }^{24}$ Ayrıca bu beş Vincetoxicum taksonunun kök ve toprak üstü kısımlarından elde edilen etanol ekstreleri antimikrobiyal aktiviteleri için dokuz mikroorganizmaya karşı (S. aureus, B. subtilis, E. coli, A. baumannii, A. hydrophila, M. tuberculosis, C. glabrata, C. parapsilosis ve $C$. tropicalis) test edilmiş ve ekstrelerin tamamı $A$. baumannii'ye karşı referans ilaç Ampisilinden (MiK değeri: $125 \mu \mathrm{g} / \mathrm{mL}$ ) daha etkili bulunmuştur; özellikle $V$. canescens subsp. pedunculata'nın kökleri ve $V$. fuscatum subsp. boissieri'nin toprak üstü kısımları 31.25 $\mu \mathrm{g} / \mathrm{mL}$ MiK değeri ile en etkilileri olarak tespit edilmiştir. Dahası test edilen ekstrelerin antifungal 
aktivitelerinin de olduğu ancak etkinliğin referans ilaç Flukonazole göre düşük olduğu belirlenmiştir. ${ }^{19}$ Bir başka çalışmada içlerinde bu araştırmaya konu olan iki taksonunda yer aldığı dört Vincetoxicum taksonunun tohum zarflarından elde edilen etanol ekstreleri antimikrobiyal aktiviteleri için S. aureus, B. subtilis, A. baumannii, E. coli, A. hydrophila, M. tuberculosis, C. glabrata, C. tropicalis ve $C$. parapsilosis'e karşı test edilmiş ve $A$. baumannii'ye karşı test edilen tüm ekstreler Ampisilinden daha etkili bulunmuştur. $V$. canescens subsp. canescens ve $V$. cancescens subsp. pedunculata tohum zarflarının etanol ekstrelerinin Mik değeri $62.5 \mu \mathrm{g} / \mathrm{mL}$ olarak belirlenmiştir. Test edilen ekstrelerin ayrıca antifungal aktivitesi olup $V$. canescens subsp. canescens ve $V$. cancescens subsp. pedunculata tohum zarflarının etanol ekstrelerinin Мik değerlerinin 31.25-62.5 $\mu \mathrm{g} / \mathrm{mL}$ aralığında olduğu tespit edilmiştir; fakat referans ilaç Flukonazol kadar etkili olmadıkları görülmüştür. ${ }^{20} \mathrm{Bu}$ çalışmada ise $V$. canescens subsp. canescens ve $V$. cancescens subsp. pedunculata tohumlarının etanol ve hekzan ekstreleri antimikrobiyal aktiviteleri için ilk kez araştırılmış ve her iki bitkinin iki farklı ekstresinin de test edildikleri bakteri ve fungusların büyümesini inhibe ettiği tespit edilmiştir. Etanol ekstreleri hekzan ekstrelerine göre daha etkili bulunmuştur. Etanol ekstreleri özellikle Gram-negatif nozokomiyal patojen A. baumannii'ye (MiK değeri: $62.5 \mu \mathrm{g} / \mathrm{mL}$ ) karşı referans ilaç Ampisilinle karşılaştırıldığında (MiK değeri: $125 \mu \mathrm{g} / \mathrm{mL}$ ) çok etkili bulunmuştur. Gram-negatif bakteriler Gram-pozitif bakterilere göre doğal bileşiklere daha dirençlidir ${ }^{29}$, hücre duvarlarının yapısı ise daha farklı ve komplekstir. Bu durum her iki bakteri grubunda makromoleküllerin alımını farklı şekilde etkilemektedir. ${ }^{30} \mathrm{Gram}$-negatif bakterilerin lipopolisakkarit içeren hidrofilik yapılı hücre duvarları hidrofobik yağlar, steroitler ve bitki ekstrelerinin emilimini ve hedef hücre zarında birikimini inhibe etmektedir. ${ }^{29} A$. baumannii kendisine karşı kullanılan antibakteriyal ilaçlara karşı direnç geliştirme yeteneğinde olan; Dünya genelinde ciddi sağlık sorunlarına yol açan bir patojendir. ${ }^{31}$ Yoğun bakım ünitelerinde görülen enfeksiyonlardan sorumlu olup son dönemde oldukça dikkat çekmektedir. Dahası geniş aralıkta enfeksiyonlardan (idrar yolu enfeksiyonları, bakteriyemi, menenjit, vantilatör kaynaklı zatürre, kan dolaşımı ve cerrahi yara enfeksiyonları) sorumludur. ${ }^{32}$ Bu çalışmadan elde edilen bulgular yukarıda bahsedilen literatür verileri ile uyumlu olup test edilen iki taksonun tohumlarının $A$. baumannii'nin neden olduğu enfeksiyonların tedavisinde umut verici antimikrobiyal ajanlar olabileceğini göstermektedir.

Literatür verilerine göre akciğer kanseri yüksek ölüm oranlarıyla malignant tümörler arasında en yaygın olan kanser türlerinden biri olup 2035 yılında 3 milyon ölüme neden olacağı beklenmektedir. ${ }^{33}$ Bu çalışmada A549 insan akciğer kanseri hücre dizilerine karşı $V$. canescens subsp. canescens ve $V$. cancescens subsp. pedunculata taksonlarının tohumlarının antiproliferatif etkileri test edilmiş ve her iki bitkinin tohumunun antiproliferatif özelliğinin olduğu belirlenmiştir. Etanol ekstrelerinin daha etkili olduğu görülmüştür. Test edilen konsantrasyonlar arasında $(25,50,100$ ve $200 \mu \mathrm{g} / \mathrm{mL}), V$. canescens subsp. canescens tohumlarının etanol ekstresinin $100 \mu \mathrm{g} / \mathrm{mL}$ konsantrasyonu ve $V$. cancescens subsp. pedunculata tohumlarının etanol ekstresinin $200 \mu \mathrm{g} / \mathrm{mL}$ konsantrasyonu kontrol gruplarına göre en düşük hücre canlılı̆ı düzeylerine neden olmuştur. Literatürde $V$. hirundinaria türünün toprak üstü kısımlarının in vitro sitotoksik aktivitelerinin ilaç duyarlı KB-3-1 ve çoklu ilaç dirençli KB-V1 kanser hücre dizilerine karşı test edildiği ${ }^{17,34}$ görülmüş olup Vincetoxicum cinsine ait türlerin tohumları ile ilgili bir araştırmaya rastlanmamıştır.

Çalışmada elde edilen antimikrobiyal ve antiproliferatif aktivite sonuçları etanol ekstrelerinin hekzan ekstrelerinden daha etkili olduğunu göstermiştir. Literatürde Vincetoxicum cinsine ait türlerin çeşitli fitokimyasalları içerdiği bildirilmiştir. ${ }^{11,17,21,22} \mathrm{~V}$. canescens subsp. canescens ve $V$. cancescens subsp. pedunculata taksonları üzerinde yaptığımız fitokimyasal araştırmalar sonucunda köklerinde şeker, steroidal glikozitler ve nişasta22; toprak üstü kısımlarında ise alkaloit (fenantroindolizidin alkaloitler), flavonoit, kardiyoaktif glikozitler ve şeker ${ }^{21}$ bulunduğu tespit edilmiştir. Literatür taramaları polisakkaritler, steroller ${ }^{29}$, flavonoitler, fenolik asitler, alkaloitler, tanenler, saponinler, terpenler ve uçucu yağları ${ }^{35,36}$ antimikrobiyal özelliklerinin olduğunu göstermiştir. Etanol, geniş aralıkta polar bileşikleri çözen ${ }^{37}$; fenolikler, alkaloitler, steroller ve terpenler ${ }^{36}$ için uygun bir çözücüdür. Bu durum, çalışmamızda etanol ekstrelerinin neden daha etkili olduğunu da açıklamaktadır.

Sonuç olarak bu çalışmada Vincetoxicum cinsine ait tohumlar ilk kez araştırılmıştır. Sonuçlar $V$. canescens subsp. canescens ve $V$. cancescens subsp. pedunculata tohumlarının tıbbi potansiyeli olduğunu göstermektedir. Bu durum iki taksonun ileri araştırmalarla farklı mikroorganizmalar ve çeşitli kanser hücre dizilerine karşı detaylı incelenmesinin ve ayrıca gelecekte Vincetoxicum cinsine ait diğer türlerin 
tohumlarının da araştırılmasının yolunu açmaktadır. Dahası ileri aşamada etkiden sorumlu bileşikler, ekstre bileşik etkinliğinin karşılaştırılması, etki mekanizmaları, hayvan deneyleri ve toksisite testlerinin de yapılması gerekliliği ortaya çıkmaktadır. Böylece, araştırmamızın bu bitkilerin enfeksiyon hastalıklarının tedavisinde antimikrobiyal ajan olarak ve çeşitli kanser türlerine karşı antiproliferatif ajan olarak kullanımlarının uygun olup olmayacağının değerlendirilmesi için yeni araştırmalara öncülük edeceği düşünülmektedir.

\section{BILGi}

Bitki örneklerinin teşhisinde katkılarından dolayı Dr. Ahmet İlçim'e (Biyoloji Bölümü, Fen-Edebiyat Fakültesi, Mustafa Kemal Üniversitesi) teşekkür ederiz.

\section{Kaynaklar}

1. Pașca C, et al. Medicinal plants based products tested on pathogens isolated from Mastitis Milk. Molecules 2017;22:1473-1489.

2. Siddiqui W, et al. Antimicrobial properties of teas and their extracts in vitro. Crit Rev Food Sci Nutr 2016;56(9):1428-1439.

3. Ngezahayo J, et al. In vitro study of five herbs used against microbial infections in Burundi. Phytother Res 2017;31:1571-1578.

4. Guzel S, et al. Wound healing properties, antimicrobial and antioxidant activities of Salvia kronenburgii Rech. f. and Salvia euphratica Montbret, Aucher \& Rech. f. var. euphratica on excision and incision wound models in diabetic rats. Biomed Pharmacother 2019;111:1260-1276.

5. Anadozie, SO, et al. Bryophyllum pinnatum inhibits arginase II activity and prevents oxidative damage occasioned by carbon tetrachloride $\left(\mathrm{CCl}_{4}\right)$ in rats. Biomed Pharmacother 2018;101:8-13.

6. Leimu R. Variation in the mating system of Vincetoxicum hirundinaria (Asclepiadaceae) in peripherial island populations. Ann Bot 2004;93:107-113.

7. Liede S. Cynanchum-Rhodostegiella-Vincetoxicum-Tylophora (Asclepiadaceae): new considerations on an old problem. Taxon 1996;45:193-211.

8. Sliumpaite I, et al. Antioxidant properties and phenolic composition of swallow-wort (Vincetoxicum lutea L.) leaves. Ind Crops Prod 2013;45:74-82.

9. DiTommaso A, Lawlor FM, Darbyshire SJ. The biology of invasive alien plants in Canada 2. Cynanchum rossicum (Kleopow) Borhidi (=Vincetoxicum rossicum (Kleopow) Barbar.) and Cynanchum louseae (L.) Kartesz \& Gandhi (= Vincetoxicum nigrum (L.) Moench). Can J Plant Sci 2004;85:243-263.

10. Mansoor A, et al. Antiprotozoal activities of Vincetoxicum stocksii and Carum copticum. Bangladesh J Pharmacol 2011;6:51-54.

11. Nowak R, Kisiel W. Hancokinol from Vincetoxicum officinale. Fitoterapia 2000;71:584-586.

12. Lavault M, Richomme P, Bruneton J. New phenantroindolizidine N-oxides alkaloids isolated from Vincetoxicum hirundinaria Medic. Pharm Acta Helv 1994;68:225-227.

13. Coassini-Lokar L, Poldini L. Herbal remedies in the traditional medicine of the Venezia Giulia Region (North East Italy). J Ethnopharmacol 1988;22:231-278.

14. Baytop T, Türkiye'de bitkiler ile tedavi geçmişte ve bugün. (ilaveli 2. Baskı), Istanbul Üniversitesi Eczacılık Fakültesi, Nobel Tıp Kitap Evleri, istanbul; 1984.pp:372.

15. Tuzlacı E, Dogan A. Turkish folk medicinal plants, IX: Ovacık (Tunceli). Marmara Pharm J 2010;14:136-143.

16. Altundag E, Ozturk M. Ethnomedicinal studies on the plant resources of East Anatolia, Turkey. Procedia Soc Behav Sci 2011;19:756-777.

17. Staerk D, et al. In vitro cytotoxic activity of phenantroindolizidine alkaloids from Cynanchum vincetoxicum and Tylophora tanakae against drug-sensitive and multidrug-resistant cancer cells. J Nat Prod 2002;65:1299-1302.

18. Zaidi MA, Crow JSA. Biologically active traditional medicinal herbs from Balochistan, Pakistan J Ethnopharmacol 2005;96:331334.

19. Guzel S, et al. Evaluation of antimicrobial activity of five Vincetoxicum taxa growing in Turkey. Mamar Pharm J 2018;22(3):365373.

20. Guzel S, Ulger M, Kokdil G. Anti(myco)bacterial and antifungal activities of seed pods of four Vincetoxicum taxa growing in Turkey. International Journal of Scientific and Technological Research 2018;4(3):27-38.

21. Guzel S, et al. Phytochemical composition and antifeedant activity of five Vincetoxicum taxa against Spodoptera littoralis and Leptinotarsa decemlineata. Mamar Pharm J 2017;21(4):872-880.

22. Guzel S, Pavela R, Kokdil G. Phytochemistry and antifeedant activity of root extracts from some Vincetoxicum taxa against Leptinotarsa decemlineata and Spodoptera littoralis. JBiopest 2015;8(2):128-140.

23. Browicz K. Vincetoxicum N.M. Wolf. In: Davis, P.H. (Eds), Flora of Turkey and the East Aegean Islands. Vol 6, Edinburgh; 1978.pp:163-173.

24. Guzel S, Pavela R, Kokdil G. Evaluation of antifungal effect of different polarity extracts from five Vincetoxicum taxa against Aspergillus fumigatus. International Anatolian Academic Online Journal/Health Science 2015;3(2): 1-9. 
25. NCCLS. Reference method for broth dilution antifungal susceptibility testing of yeasts; approved standard, second ed. NCCLS document M27-A2 (ISBN 1-56238-469-4); Wayne; Pennsylvania; 2002.

26. Yumrutas $\mathrm{O}$, et al. Association between anti-proliferative activity of Evernia prunastri with the cellular apoptotic pathway. Cumhuriyet Sci J 2017;38(3):516-524.

27. Bazzaz F, Haririzadeh G. Screening of Iranian plants for antimicrobial activity. Pharm Biol 2003;41(8):573-583.

28. Mogg $C$, et al. Test of the antibiotic properties of the invasive vine Vincetoxicum rossicum against bacteria, fungi and insects. Biochem Syst Ecol 2008;36:383-391.

29. Bajpai VK. Antimicrobial bioactive compounds from marine algae: a mini review. Indian J Geomarine Sci 2016;45(9):1076-1085.

30. Alimpić A, et al. Biological activities and chemical composition of Salvia amplexicaulis Lam. extracts. Ind Crops Prod 2017;105:19.

31. Lean SS, Yeo CC. Small, enigmatic plasmids of the nosocomial pathogen, Acinetobacter baumannii: good, bad, who knows? Front Microbiol 2017;8:1547-1555.

32. Shamsizadeh Z, et al. Detection of antibiotic resistant Acinetobacter baumannii in various hospital environments: potential sources for transmission of Acinetobacter infections. Environ Health Prev Med 2017;22(44):1-7.

33. Sak K, et al. Cytotoxic action of methylquercetins in human lung adenocarcinoma cells. Oncol Lett 2018;15:1973-1978.

34. Staerk D, et al. Cytotoxic activity of some phenanthroindolizidine $N$-oxide alkaloids from Cynanchum vincetoxicum. J Nat Prod 2000;63:1584-1586.

35. Arif T, Mandal TK, Dabur R. 9. Natural products: Anti-fungal agents derived from plants. In: Mishra, B.B. (Eds), Opportunity, Challenge and Scope of Natural Products in Medicinal Chemistry. Kerala; 2011.pp:283-311.

36. Cowan M.M. Plant products as antimicrobial agents. Clin Microbiol Rev 1999;12(4):564-582.

37. Kowalczyk D, et al. The phenolic content and antioxidant activity of the aqueous and hydroalcoholic extracts of hops and their pellets. J Inst Brew 2013;119(3):103-110. 